\title{
A circulação de fórmulas discursivas em livros ilustrados
}

Patricia Ferreira Neves Ribeiro*

\section{Resumo}

Nesta pesquisa, procede-se à investigação do emprego de fórmulas discursivas - conforme definição de Alice Krieg-Planque (2010) - e de suas alterações em livros infantis ilustrados. Considerando-as como um produtivo espaço para a difusão da estereotipia - da perspectiva de Amossy (1991) e Amossy e Hershberg Pierrot (1997) - e de seu simultâneo deslocamento, deseja-se problematizar o uso de fórmulas discursivas (re)enunciadas no universo dos livros ilustrados para crianças, com vistas a esclarecer os possíveis jogos de poder instaurados e a contribuir para a formação do leitor "aprendiz". Com efeito, deseja-se verificar se as fórmulas (re)enunciadas funcionam apenas como um regime próprio de citação de enunciados (des)cristalizados, ou como, efetivamente, mecanismos estratégicos para a construção de determinados sentidos, os quais "falam" discursivamente sobre a maneira como os valores e princípios de uma comunidade são postos em narrativa e sustentam certos imaginários sociodiscursivos - conforme noção tomada da semiolinguística de Charaudeau (2006, 2007, 2008, 2010). Para a realização do estudo, esta pesquisa debruça-se sobre um corpus formado pelos livros No caminho de Alvinho tinha uma pedra..., de Ruth Rocha e Ivan Zigg, e Julieta de bicicleta, de Liana Leão e Márcia Széliga. No âmbito dos procedimentos de análise, o corpus é submetido a uma "radiografia" feita em nível qualitativo, visando à descrição e à avaliação das opções sintático-semânticas e lexicais de (re)construção das fórmulas discursivas. Como fundamentação teórica, adota-se, também, para a confecção do trabalho, no quadro da teoria francesa de análise do discurso, a noção de détournement, cunhada por Gréssilon e Maingueneau (1984).

Palavras-chave: Fórmula discursiva. Reenunciação. Imaginário sociodiscursivo.

Docente Adjunto II do Programa de Pós-Graduação em Estudos de Linguagem da Universidade Federal Fluminense (UFF). Membro do projeto integrado de pesquisa Ciad-Rio (Círculo Interdisciplinar de Análise do Discurso). E-mail: patleitura@gmail.com.

Data de submissão: abr. 2013 - Data de aceite: ago. 2013 http://dx.doi.org/10.5335/rdes.v9i2.3857 


\section{Introdução: o início do caminho}

Nesta pesquisa, propõe-se a investigação de expressões (des)cristalizadas em livros ilustrados, com vistas a esclarecer jogos de poder ali instaurados e modos de leitura ali inscritos. Em outros termos, procede-se, neste artigo, ao exame de fórmulas discursivas (re) enunciadas, visando não só refletir sobre os imaginários sociodiscursivos (CHARAUDEAU, 2006) que lhes são correspondentes, como também sobre possíveis construções de leitura que perpassam o universo da literatura infantil.

Sendo as expressões (des)cristalizadas, ou ainda, as fórmulas discursivas e suas alterações, campo fértil para a difusão da estereotipia e, por vezes, de seu simultâneo deslocamento, deseja-se problematizar seu uso em livros ilustrados, cujo público é (também) a criança. Assim, o emprego de livros para crianças como corpus deste trabalho, para apreensão de fórmulas discursivas e de suas derivações, justifica-se, primordialmente, pelo fato de ser possível mostrar como o leitor aprendiz pode ser inserido nessa problematização, isso é, na "densidade história que se presentifica" (MOTTA e SALGADO, 2011, p. 5) na circulação das fórmulas discursivas.

Esse emprego constitutivo, e não ornamental, de sequências (des)cristalizadas faz delas lugar privilegiado de produção de sentido, uma vez que possibilita a inscrição de crenças, valores e princípios no texto. Com efeito, deseja-se pensar como o leitor é afetado por esse dizer alheio sintético que assevera - mediante jogos de poder calcados naquelas crenças, valores e princípios - ora vozes mais consensuais, ora mais questionadoras diante de uma comunidade.

Para a confecção do trabalho, adota-se uma orientação teórica em que são conjugadas as noções de estereótipo, especialmente da perspectiva de Amossy (1991) e Amossy e Hershberg Pierrot (1997), de fórmula discursiva, proposta por Alice Krieg-Planque (2010) e de détournement, cunhada por Gréssilon e Maingueneau (1984).

O corpus selecionado para esta pesquisa compreende os livros No caminho de Alvinho tinha uma pedra... (1993), de Ruth Rocha e Ivan Zigg, e Julieta de bicicleta (2005), de Liana Leão e Márcia Széliga, os quais incorporam fórmulas e suas reenunciações.

Além disso, no âmbito dos procedimentos de análise, o corpus é submetido a uma "radiografia" feita em nível qualitativo. Frente à natureza da pesquisa, é feita a descrição e a avaliação das opções sintático-semânticas e lexicais de (re)construção das fórmulas, a fim de examinar os jogos intertextuais que, a partir daí, manifestam-se e que são marcadores discursivos das crenças, princípios e valores de dada comunidade. As análises que emergem dos dados são associadas também aos modos de leitura inscritos nos livros selecionados, os quais disseminam "polos ideológicos" sobre a formação do leitor. 


\section{Para um caminho seguro}

No sentido dado pela análise do discurso, Charaudeau e Maingueneau mostram que o estereótipo é, "com os topoi ou lugares-comuns, uma das formas adotadas pela doxa, ou conjunto de crenças e opiniões partilhadas que fundamentam a comunicação e autorizam a interação verbal" (2004, p. 215). O estereótipo é o alicerce sobre o qual os interlocutores apoiam-se para estabelecer comunicação, ação entre si. Isso se explica porque a palavra alheia, inscrita nos enunciados, é sempre retomada e respondida na interação verbal. Todo enunciado constrói-se, portanto, sobre estereótipos, isso é, "sobre o já-dito e o já-pensado que ele modula e, eventualmente, transforma" (CHARAUDEAU e MAINGUENEAU, op.cit., p. 216).

Pensando em algumas enunciações-síntese como um fenômeno de estereotipia, é possível defini-las como uma representação coletiva cristalizada. Sendo essa representação estereotipada, tais enunciações circulam pelas trocas verbais não só indicando a intrínseca necessidade de se estabelecer normas de conduta aos homens de certa comunidade, mas também revelando os ajustes pelos quais passam os valores instrutivos que divulgam. Portanto, a cristalização, sob a qual enunciações-síntese estruturam-se, está longe de esgotar seu valor discursivo, porque, como se pode ver, na prática, estão abertas a muitas ressignificações.
Por sua vez, Amossy (1991) e Amossy e Herschberg Pierrot (1997) estabelecem que, em diferentes níveis, as formulações estereotipadas integram a construção do sentido do texto. Segundo esses autores, sendo entendidos como representações ou imagens coletivas cristalizadas e esquemas culturais preexistentes compartilhados socialmente - os estereótipos permitem a inscrição do social e do histórico no texto de que são formas constitutivas.

Schapira (1999), por seu turno, organiza os estereótipos sob duas categorias, a saber: os estereótipos de pensamento e os estereótipos linguísticos. Por um lado, os estereótipos de pensamento - transmitidos culturalmente - são partilhados, como representações comuns, pelos membros de uma comunidade social. Os estereótipos linguísticos, por outro lado, apresentam-se como estruturas, relativamente fixas, em uma língua.

Amossy e Herschberg Pierrot (1997) identificam os estereótipos linguísticos não somente a locuções de diferentes tipos, tais como - construções cotidianas da habitual dinâmica da conversação; slogans; formulações típicas de cortesia - mas também a construções proverbiais, alçadas à condição de estereótipos argumentativos e didáticos, enraizados em remota tradição da sabedoria popular.

Os estereótipos linguísticos são fixados na memória de uma comunidade linguística, após serem adquiridos pelos falantes com o conhecimento e o uso da língua. Além disso, são enunciados 
genéricos que, mesmo transportados para situações específicas de enunciação, definem-se por promover uma relação convencional, consensualmente partilhada, entre a estrutura sintática e o conceito nomeado acerca de valores de um grupo social. Quando introduzidos, os estereótipos linguísticos, sendo mecanismos para a difusão de sentidos consensualmente instituídos, facilitam a compreensão por parte do interlocutor.

Dentro do escopo desta pesquisa, examina-se a estereotipia linguística para que se apreendam em um corpus constituído por dois livros ilustrados para crianças - cujo ato de ler é mediado pelo leitor adulto - os discursos que a modelam e que a fazem circular. Acredita-se que esses discursos alimentem a prática linguageira da estereotipia com o que foi pré-fixado pelo consenso, mas também com o que é modulado pela singularidade, numa espécie de continuum. $\mathrm{Na}$ constituição de um modo de leitura eficaz para os referidos livros, é essencial a investigação desse continuum, no que pese a natureza do próprio fenômeno linguageiro.

Com vistas à execução do que se postula neste artigo, é necessário, como já mencionado, recorrer também à noção de fórmula proposta por Alice Krieg-Planque (2010). Essa recorrência é necessária, sobretudo, para que se refine o conceito de estereotipia sobre o qual se debruça este trabalho.

Consoante Krieg-Planque (2010, p. 67) "a fórmula tem um caráter cris- talizado pelo qual ela se identifica com uma materialidade linguística particular", podendo, contudo, existir por meio de variadas paráfrases das quais é a cristalização, o que inibe a imposição de um formalismo absoluto sobre o referido conceito. Vale ressaltar, entretanto, que essa fórmula não existe fora de uma sequência cristalizada bem identificável que condensa as múltiplas paráfrases.

Nesse sentido, os estereótipos de pensamento não são fórmulas, uma vez que não são coconstruídos por uma "sequência verbal estável e repetida” (2010, p. 69). Desse modo, no trabalho proposto, a análise recai, essencialmente, sobre os estereótipos linguísticos - entendidos como fórmulas - e sobre suas derivações.

Sobre quatro pilares sustenta-se o conceito de fórmula. Na concepção de Krieg-Planque (2010), uma fórmula: a) tem um caráter cristalizado; b) assume uma perspectiva discursiva; c) exerce papel de referente social; d) abriga um aspecto polêmico. Dentro dessa perspectiva teórica, ressalta-se que essas quatro propriedades podem apresentar-se de maneira desigual, sendo cada uma delas mais ou menos verificável na enunciação da fórmula. São, nos termos de Planque (2010, p. 111), "verificáveis em continua, e não mensuráveis em termos de presença ou ausência".

Para a autora (op. cit., p. 112),

$\mathrm{O}$ fato de a fórmula ser um objeto inscrito em um continuum não faz dela, de modo algum, um objeto totalmente acientífico que resiste a uma análise fundamentada. Ao contrário, o caráter contínuo do objeto - e 
consequentemente, a grande diversidade de silhuetas e figuras sob as quais será possível encontrá-lo - faz da noção de fórmula uma noção heurística, suscetível de ser sempre recolocada, revisitada, redefinida.

A fim de examinar a tênue linha divisória que vai da cristalização formulaica à sua alteração, é necessário, ainda, somar à fundamentação teórica já delineada outro conceito fundamental extraído de Gréssilon e Maingueneau (1984): o détournement ou o desvio, que consiste em "produzir um enunciado que possui marcas linguísticas de uma enunciação proverbial, mas que não pertence ao estoque de provérbios reconhecidos" (op. cit., p. 114) e que compreende tanto casos de captação quanto de subversão.

\section{Abrindo caminhos}

Entre tantos enunciados e especificidades enunciativas a serem capturados para análise dos livros ilustrados, elegeu-se, como já exposto, o espaço do aparente apaziguamento das fórmulas discursivas; apenas aparente, uma vez que as fórmulas estão sempre em movimento, submetidas a constantes alterações.

Mais especificamente, são destacadas para análise duas distintas enunciações-síntese. A primeira delas intitula uma das obras de Ruth Rocha e Ivan Zigg, No caminho de Alvinho tinha uma pedra... . A segunda é fragmento extraído do livro de Liana Leão e Márcia Széliga, Julieta de bicicleta: "Até que um dia uma pedra no caminho atrapalhou Julieta".
Ao circularem, essas enunciações remetem à famosa máxima: "No meio do caminho tinha uma pedra", extraída do célebre poema de Carlos Drummond de Andrade - No meio do caminho - publicado, pela primeira vez, em 1928.

Embora a referida fórmula tenha conquistado autonomia e sido, portanto, integrada ao repertório de expressões populares do país, a construção "No meio do caminho tinha uma pedra" pode, entretanto, sugerir uma remissão paródica ao início da obra de Dante, $A$ divina comédia (ARRIGUCCI JR., 2002).

Nesse sentido, o poema de Drummond ecoa certa errância sofrida - descrita no percurso do poeta moderno - que, diante do próprio ato inaugural da criação, apresenta-se, ironicamente, já fatigado - "Nunca me esquecerei desse acontecimento/ na vida de minhas retinas tão fatigadas" (DRUMMOND, 1928). E essa fadiga é a do "caminho infindável, que mais parece impedimento que via certa do encontro." (ARRIGUCCI JR., op.cit., p. 73).

No meio do caminho, o que se encontra é a pedra irremovível, que corrói a alma ensimesmada e abatida. Reduzido a uma situação narrativa básica, o poema conta um acontecimento, qual seja o "do caminhante que se defronta com o obstáculo - situação essa que se converte no drama íntimo de quem se abate diante da barreira." (ARRIGUCCI JR., op. cit., p. 72).

Inegavelmente, os ditos reenunciados - "No caminho de Alvinho tinha uma 
pedra..." e "Até que um dia uma pedra no caminho atrapalhou Julieta" - apontam para a recorrência desse significante drummondiano, cuja integridade ("no meio do caminho tinha uma pedra") ou pista ("pedra") é possível seguir. Diante das reenunciações, o interlocutor captura a circulação de um significante estável e em constante repetição. Tal estabilidade faz-se necessária para seu funcionamento como significante partilhado. Assim, as novas fórmulas fazem ressoar uma que lhes é anterior e sobre a qual estão calcadas. A partir dela, entretanto, propõem novos efeitos de sentido.

Considerando as reenunciações a seguir: "No caminho de Alvinho tinha uma pedra..." e "Até que um dia uma pedra no caminho atrapalhou Julieta", em paralelo à versão original: "No meio do caminho tinha uma pedra", verifica-se que se trata de derivações que resultam de diferentes processos de retextualização (MARCUSCHI, 2004), os quais figuram em uma associação sintagmática - "no caminho tinha uma pedra" - de certo modo, bloqueada.

O termo "retextualização" é entendido como uma espécie de "tradução", como uma forma de "reescrita", que produz mudanças de um texto para o outro; ambos pertencentes, entretanto, à mesma língua. Essa atividade de transformação textual pode ocorrer por apelo a processos de substituição, de acréscimo, de supressão e de fusão e pode envolver mudanças na forma das expressões cristalizadas em metáforas, ritmo e construção.
Diante do primeiro fragmento, observa-se que o enunciado derivado conserva o dito original, mas efetua alterações no interior da locução adverbial "no meio do caminho". Essas modificações ocorrem por apelo tanto ao recurso da supressão quanto ao do acréscimo de itens lexicais. Tal versão é resultado da exclusão dos termos "meio" e "do", e, ao mesmo tempo, da inserção da locução adnominal "de Alvinho" e das reticências ao final do fragmento reenunciado, no qual a arquitetura sintática mais ampla é preservada, atendo-se, inclusive, ao modelo hospedeiro da versão original ( $\mathrm{SAdv}+$ verbo ter $+\mathrm{SN})$.

Analisando a segunda construção derivada, verifica-se também o uso da estratégia da supressão aliada à do acréscimo. São suprimidos, na versão inédita, os termos "meio" e "do" do adjunto adverbial, assim como se alarga o dito convencional pela inclusão da expressão "Até que um dia" e do verbo e de seu complemento: "atrapalhou Julieta”. A configuração sintática da oração é alterada, uma vez que o sintagma "uma pedra" é alçado, na nova construção, à condição de sujeito, cuja ação recai, na explicitação da estrutura sintática, sobre o objeto "Julieta".

As alterações propostas relativamente à construção original não invalidam, contudo, a propriedade de cristalização de ordem memorial - que as caracteriza e que as pode conduzir à versão primeira. Esse paralelismo que recobre a parte significante da fórmula não deixa o leitor perder de vista a voz matriz. 
Por outro lado, se é verdade que essas formulações concorrentes da fórmula original inserem-se num quadro de "pertencimento morfossintático e lexical" relativamente à fórmula original, é verdade também que tais formulações apontam para uma "instabilidade fundamental dos significados". Em outros termos, as construções derivadas funcionam como concorrentes das formas primitivas, do ponto de vista sociopragmático, ao encerrarem uma espécie de bifurcação entre o senso comum e seu deslocamento para o universo da obra em que se inserem.

Por sua vez, esse deslocamento é sintomático do uso discursivo que se faz da fórmula "No meio do caminho tinha uma pedra", uma vez que exibe a produção de diferentes julgamentos acerca da temática em questão. A propósito, no que concerne a essa dimensão discursiva, atente-se para o fato de que é seu uso linguageiro - circunscrito social e historicamente - que desencadeia o percurso da sequência para o alcance do caráter formulaico. Além disso, enquadrar a fórmula numa configuração discursiva equivale a vê-la no papel de um referente social.

Cada vez que é retomada, a fórmula põe em evidência seu papel de referente social, ou seja, a função de ser uma sequência material por que passam, obrigatoriamente, os discursos produzidos no espaço público num determinado período. Isso leva à dimensão do caráter notório da fórmula. Diante de tal notoriedade, como bem elucida Salgado, "todos são chamados a assumir alguma posição em relação ao que está condensado no material linguístico cristalizado, sintetizador de usos, de retomadas." (2011, p. 155).

Para que se flagre a heterogeneidade de posições frente à fórmula focalizada, observe-se, inicialmente, o fragmento que intitula o livro de Ruth Rocha: "No caminho de Alvinho tinha uma pedra..." em contraste com a máxima: "No meio do caminho tinha uma pedra.".

A fim de acomodar o dito "No meio do caminho tinha uma pedra" à construção da narrativa proposta, o sujeito enunciador particulariza o caminho anunciado pela inserção da locução adjetiva classificatória: "de Alvinho". Estabelece-se, neste caso, uma relação semântica de posse entre Alvinho e o termo a que se refere: "o caminho".

Por meio da introdução da locução "de Alvinho", a generalização e a atemporalidade, intrínsecas aos ditos populares, são direcionadas para um fato particular, localizado no tempo e no espaço, de acordo com a histórica narrada. Isso comprova o que Mondada e Dubois, no âmbito da teoria da referenciação (2003) demonstram acerca dos objetos sociais. No discurso, o que é normalmente tomado como uma categoria referencial estável pode tornar-se instável, por consequência de uma mudança de contexto ou de ponto de vista. No "aqui" e no "agora" do texto elaborado, a ausência de um agente (o caminho é de qualquer um), estabilizada na versão canônica, torna-se instável pela inserção da expressão "de Alvinho". 
Para contextualizar, é válido resgatar a história narrada. No referido texto, Alvinho - "menino gorduchinho" e falante - é apresentado segundo a mania que tem "de levar para casa tudo que ele encontra". Num belo dia, o menino leva para casa, supostamente, uma pedra grande e redonda. Protegida debaixo de sua cama, o menino descobre que a pedra era um ovo de avestruz. Passa então a cuidar do animal sem deixar que sua mãe perceba a presença do bicho. $\mathrm{O}$ que parecia mesmo inevitável acontece. A mãe de Alvinho descobre o avestruz escondido no quarto do filho e começa a algazarra, que somente termina quando a ave é mandada para o jardim zoológico.

É a esse enredo que a fórmula derivada dá título e é, nesse contexto, que deve ser analisada a fim de que se investigue a flutuação semântica da construção fonte e seus correspondentes imaginários sociodiscursivos.

O conceito "de entrave" interposto na vida de qualquer ser humano, metaforicamente sustentado pela fórmula original é, de certo modo, subvertido na versão derivada, uma vez que o dito é orientado para um sentido diferente do original. Nesse caso, a reenunciação é concebida como um détournement ou desvio que comporta a estratégia da subversão. No interior da história comentada, estabelece-se uma divergência entre o que apregoa a versão convencional e o que a nova instaura. E é justamente por essa brecha da divergência, marcada discursivamente, que capturamos os diferentes imaginários sociodiscursivos constituídos a partir da fórmula selecionada.

Na obra de Ruth Rocha e Ivan Zigg, a leitura da máxima (que "vive" na instância linguageira drummondiana), baseada na metáfora "dificuldades (pedras) são impedimentos para o deslocamento (caminho)", é, inicialmente, cancelada. Favorece-se, nesse primeiro momento do novo contexto, uma construção de leitura calcada na simbolização referencial ${ }^{1}$ dos termos "pedra" e "caminho", conforme se vê nos trechos retirados da obra: "Pois o Alvinho tem a mania de levar pra casa tudo que ele encontra... Pedra, bicho, tudo que é lixo..." e "No outro dia, Alvinho trouxe pra casa uma pedra. Era uma pedra grande e redonda".

Em consequência, com base na leitura referencial dos termos "pedra" e "caminho", o efeito de sentido produzido é outro. O mineral "pedra" é algo agradável - um bem - que se encontra no espaço público - "E todo dia, quando chegava do colégio, Alvinho corria pro quarto, pra ver se o seu tesouro ainda estava lá".

O jogo da recriação é permitido uma vez que objetos concretos podem ser, efetivamente, encontrados, "catados" ("cata tudo") numa via, num caminho: "Pois o Alvinho cata tudo!". Além disso, mais especificamente, a leitura do termo "pedra", segundo sua referencialidade, é favorecida - no interior desse novo universo do discurso - em virtude de o citado mineral integrar, paradigmaticamente, uma lista cujos itens podem 
ser apreciados conforme sua natureza concreta, como: "berloque", "latinha", "parafuso", dentre outros: "Pois o Alvinho cata tudo! Desde berloque, canudo, barbante, escama, tampinha, pau de sorvete, latinha até besouro chifrudo!". Com efeito, anula-se, inicialmente, a metáfora consensual mais transparente: "dificuldades são impedimentos para o deslocamento", para se recobrar o sentido de "pedra" como mineral.

Além disso, constata-se que uma nova metáfora, a incidir sobre o item "pedra", parece ser delineada no seio da obra. Identificada a pedra a um tesouro - "E todo dia, quando chegava do colégio, $\mathrm{Al}$ vinho corria pro quarto, pra ver se o seu tesouro ainda estava lá" - encerra-se a ideia de que a "pedra" é algo valioso e, como tal, algo que agrada ao menino. Nesse sentido, assume-se outra associação metafórica na totalidade discursiva do texto em questão, qual seja a de que "o agradável é valioso".

O texto abre-se a essa nova significação, sobretudo quando o menino descobre ser a pedra um ovo de avestruz: "A pedra não era pedra, era um ovão!" e "De dentro daquela pedra estava saindo um frangão". Na visão de Alvinho, o "ovo" agora é a representação de uma conquista positiva, acentuada pelo uso do sufixo aumentativo, -ão: "Alvinho ficou contente: __ Oba, oba, agora tenho um bicho diferente."

Ainda, alçando a pedra a um ovo de avestruz, rompe-se, no interior do texto, com a ideia de que a inevitável e perma- nente circularidade da pedra inserida no dito é um obstáculo à criação, seja ela poética - como sugere Arrigucci (2002, p.73): "Nela (na pedra) reside a dificuldade básica que para ele (Drummond) funda a criação: é fator desencadeante e, simultaneamente, entrave do ato poético" - ou não. No universo discursivo de No caminho de Alvinho tinha uma pedra..., a circularidade da "pedra grande e redonda" é rompida - "De dentro daquela pedra estava saindo um frangão", encerrando o claro efeito de sentido (significação) positivo do milagre da criação.

Ao mesmo tempo, contudo, mesmo transportado para uma situação específica de enunciação, o sentido metafórico consensual do termo "pedra" é mantido reconhecível, sobretudo porque sobrevive diante da situação de interlocução encenada entre o menino Alvinho e sua mãe Dona Branca. Nesse sentido, flagra-se o desvio ou détournement como um caso de captação, ao se verificar a utilização da autoridade convencional do estereótipo linguístico.

Os fragmentos a seguir comprovam que, diante de Dona Branca, as duas noções flagradas na esfera do dito derivado mesclam-se: "A mãe de Alvinho vive desesperada", "_Este menino deixa a casa toda desarrumada" e " - Ai meu Deus! Este menino traz pra casa tudo que ele encontra". A "pedra" representa um entrave à vida doméstica de Dona Branca, ao mesmo tempo em que o é como objeto que se acumula no interior 
da casa, impedindo a devida limpeza do local. Segundo apreciação de Alvinho, Dona Branca vê, de fato, a "pedra" como um obstáculo à manutenção da ordem doméstica e responde às apreensões da mãe: "Alvinho ficou com medo que Dona Branca jogasse a pedra fora. Então escondeu a pedra debaixo da cama".

Nesse caso, também, diante da descoberta de que a "pedra" era um ovão, Alvinho ressignifica o vocábulo frente à reação da mãe, ao considerá-lo, novamente, como um entrave à vida doméstica. Essa nova orientação argumentativa pode ser percebida claramente na passagem a seguir introduzida pelo operador "mas": "Mas escondeu o avestruz, pra Dona Branca não ver. Se ela visse aquele bicho, que escarcéu ia fazer", como também em muitas outras passagens que acenam as ações de esquiva do menino: "E Alvinho passou a trancar a porta do quarto quando ia pro colégio"; "Dona Branca reclamava: _Eu preciso arrumar o seu quarto, menino!/_Pode deixar que eu arrumo - o Alvinho respondia.”

A fórmula derivada, "No caminho de Alvinho tinha uma pedra...", expõe a heterogeneidade constitutiva da fórmula básica, que conduz à construção de outra significação, outros valores, outro imaginário sociodiscursivo. Recria-se, no interior da obra de Ruth Rocha, novo real discursivo justamente pela matéria formulaica que o constitui. O imaginário consensual acionado pelo dito "No meio do caminho tinha uma pedra", o qual refere os impasses da passagem do ho- mem pela vida, é, em parte, ultrapassado pela leitura multifacetada proposta pela fórmula alterada nesse texto.

Em Ruth Rocha, abre-se o conglomerado de noções que postula o termo "pedra" como signo: não se impõe à criança, surpreendentemente, a leitura consensual do dito. Isso, aliás, parece já estar configurado na opção pelo uso das reticências do título - No caminho de Alvinho tinha uma pedra... - sinal de pontuação que marca uma inflexão de natureza emocional a remeter para 0 referido efeito de surpresa.

A construção em foco transita pelas diversas noções que o signo "pedra" pode comportar, sendo elas, ora mais, ora menos consensuais. A "pedra” é tanto algo que dificulta o deslocamento, quanto o que o torna agradável. Isso revela que a significação constrói-se, de fato, no texto, não ocorrendo, previamente, à sua elaboração. Segundo Charaudeau (2008p. 26), "não se pode determinar de forma apriorística o paradigma de um signo, já que é o ato de linguagem, em sua totalidade discursiva, que o constitui a cada momento de forma específica".

O imaginário sociodiscursivo do "impasse", do "fim" e da "morte", produzido, de modo metaforicamente consensual, pelo dito "No meio do caminho tinha uma pedra" e ecoado por tantos outros estereótipos linguísticos que se centram sobre tal referente, como: "pedra no sapato"; "tirar leite de pedra"; "coração de pedra", é ultrapassado, em parte, no livro No caminho de Alvinho tinha uma pe- 
dra... Recorre-se também, nessa obra, ao imaginário do virtuoso: para Alvinho, em seu caminho, tinha (tem) "passagem", "começo" e "vida". Por isso mesmo, ele parece não descartar o hábito de levar para casa tudo com o que se depara na rua, conforme se comprova pelo trecho final da narrativa: "E o Alvinho perdeu aquela mania que ele tinha (tinha?) de levar pra casa tudo que ele via".

A fim de se constatar, mais uma vez, a variável posição de retomada diante da fórmula em discussão, examine-se, agora, a passagem inserida no livro de Liana Leão e Márcia Széiga: "Até que um dia uma pedra atrapalhou Julieta", em contraste com a versão original: "No meio do caminho tinha uma pedra".

Como já mencionado, essa reformulação, embora aluda à construção fonte, efetua mudanças por apelo tanto à supressão, quanto ao acréscimo. Essas alterações objetivam incorporar à construção original elementos pertinentes à narrativa em questão.

A propósito, a história em tela, intitulada Julieta de bicicleta, inicia-se por descrever as sistemáticas ações da menina Julieta em seu dia a dia - "Julieta acordava exatamente à mesma hora, todo dia" e "Meio-dia, hora da escola, e Julieta, empertigada, de uniforme esticadinho, limpinho, passadinho, ia andando, em uma linha absolutamente reta" - para, em seguida, no tempo da narração, contar as aflições de Julieta, frente às curvas do caminho: "Até que um dia uma pedra atrapalhou Julieta, que parou, estancou, indecisa: Que fazer?", e, especialmente, relatar a curva que a menina encontra de posse de sua nova bicicleta: "Pedalava num ritmo perfeito até que surgiu uma curva muito encurvada. Julieta estancou. Pensou: 'O que haverá depois da curva? Essa curva estraga meu caminho em linha reta'...".

Pela ampliação da fórmula tradicional, verifica-se que ela é capturada para dentro da narrativa. A expressão adverbial "Até que um dia" abre o texto para o modo de organização narrativo e insere a fórmula derivada no fio da história que se começa a narrar.

Nessa obra, assim como na anteriormente analisada, o leitor, diante da feição contemporânea do enunciado cristalizado, vê-se enredado pela possibilidade de lê-lo segundo a simbolização referencial de "pedra" como mineral. Essa afirmação confirma-se pela leitura paradigmática estabelecida entre o signo "pedra", que figura no dito reenunciado, e o termo "pedregulho", que aparece logo em seguida: "Antes que Julieta tomasse a difícil decisão, um garoto do colégio cruzou sua frente e, displicente, sem perceber, chutou o enorme pedregulho de papel machê".

A esse modo de leitura, calcado no sentido supracitado, soma-se a significação de "dificuldade" proposta pela metáfora consensual: "dificuldades (pedras) são impedimentos para o deslocamento (caminho)". Em Julieta de bicicleta, não se rompe com a interpretação automatizada proposta para a fórmula canônica; 
antes, reafirma-se a metáfora consensual mais transparente, sobretudo, pelas evidentes escolhas sintáticas e lexicais. Decorre, daí, um desvio ou détournement que faz uso da autoridade sentenciosa da máxima em prol de uma reenunciação submetida ao processo de captação.

O verbo selecionado, "atrapalhou", direciona o texto, claramente, para o sentido de "entrave" proposto pela versão original da fórmula. Ao mesmo tempo, acentua-se a ideia de que a "pedra", no papel sintático de sujeito, é "obstáculo" provocador da dificuldade que atinge Julieta - alvo da ação - em seu deslocamento.

A fórmula derivada, presente no texto em questão, evoca a original, reafirmando sua metáfora mais transparente e facilitando seu reconhecimento. E, como se isso não bastasse, a "pedra" localiza-se em rua denominada "Carlos Drummond de Andrade", ressaltando-se a intertextualidade por semelhança entre o dito reenunciado e o verso que figura no poema de Drummond, verso que se fez máxima do repertório popular.

No universo do discurso de Julieta de bicicleta, a fórmula modificada transita pelas noções que instituem a "pedra", tanto como mineral, quanto como "entrave". Especialmente, a "pedra", lida conforme a metáfora consensual, é, de fato, algo que dificulta o deslocamento. Nessa direção, percebe-se que o desvio da versão inédita da fórmula, relativamente à canônica, passa a ser mínimo. Nesse caso, portanto, reforça-se o imaginário sociodiscursivo do "impasse", do "fim" e da "morte", que circula a propósito da reenunciação "Até que um dia uma pedra atrapalhou Julieta".

\section{Considerações finais: (im)passes do caminho}

Nesta pesquisa, foi de grande interesse apreender as posições de retomada - assumidas pelos enunciadores e por seus correspondentes imaginários sociodiscursivos - diante do que se sintetizou pela fórmula discursiva "No meio do caminho tinha uma pedra".

Aliás, sendo essas retomadas às fórmulas que as instauram como centro de polêmica, evidenciou-se que a fórmula em questão fez-se ponto de passagem obrigatório, que, a cada nova enunciação, houve a construção de um referente próprio. Em outros termos, o sujeito enunciador, atravessado inevitavelmente pela fórmula, assumiu, relativamente a ela, posição, ora mais "problematizadora" "No caminho de Alvinho, tinha uma pedra..." - ora mais consensual - "Até que um dia uma pedra atrapalhou Julieta.", na rede interdiscursiva em que se situa.

Assim, neste trabalho, constatou-se a heterogeneidade constitutiva das fórmulas básicas, especialmente da construção "No meio do caminho tinha uma pedra", explicitada nas derivas analisadas - "No caminho de Alvinho, tinha uma pedra..." e "Até que um dia uma pedra atrapalhou Julieta." Pôde-se perceber como tal variabilidade produziu modos de leitura 
voltados a um conglomerado de sentidos, ora mais, ora menos constantes.

E esse continuum de sentidos - da simbolização referencial à significação - impulsionou as distintas construções de leitura relativas às obras No caminho de Alvinho, tinha uma pedra... e Julieta de bicicleta.

De um lado, apontou-se para a confirmação do imaginário sociodiscursivo do impasse, do fim e, quiçá, da morte que se interpõe na travessia - dentro daquilo que foi pré-fixado pelo consenso. De outro, a leitura construiu-se em direção a novo valor, crença e princípio - no âmbito do que foi modulado pela singularidade - uma pedra no meio do caminho pode ser símbolo da passagem, do começo, da vida, agradável ao sujeito que a encontra, em razão do valor inestimável que agrega ao percurso vivido.

\section{La circulation des formules discursives dans les livres d'images}

\section{Abstract}

We resume in this paper the investigation of the use of discourse formulae - according to the definition by Alice Krieg-Planque (2010) and their modifications in illustrated children's books. By considering them as a productive space for the propagation of stereotypy - from Amossy's (1991) and Amossy and Hershberg Pierrot's (1997) perspective - and for its simultaneous transposition, we wish to discuss the use of discourse formulae in the universe of books il- lustrated for children, with a view to clarifying the possible power games and to contributing to the learner's formation. In fact, we wish to verify if the recreated formulae work solely as a mere process of (de)crystallised utterance quotation, or as true strategic mechanisms for the constructing specific senses, which "speak" discursively about the ways the values and principles of a community are put into narrative and certain determined sociodiscursive imaginaries - according to the notion borrowed from Charaudeau's Semiolinguistics (2006, 2007, 2008, 2010). To this aim, this research focuses on a corpus that consists of Ruth Rocha and Ivan Zigg's No caminho de Alvinho tinha uma pedra... and Julieta de Bicicleta by Liana Leão and Márcia Széliga. As to the method used, the corpus is subjected to a qualitative "radiography", so as to describe and evaluate the syntactic-semantic and lexical options to the (re)creation of discourse formulae. As a theoretical grounding to this research, we have also adopted, in the framework of the French theory of Discourse Analysis, the notion of détournement, coined by Gréssilon and Maingueneau (1984).

Key words: Discourse formulae. Recreation. Sociodiscursive imaginary.

\section{Nota}

1 Para Charaudeau (2008, p. 37), o ato de linguagem resulta de uma dupla atividade: a simbolização referencial e a significação. A primeira "tende a unir uma forma material a um determinado conteúdo de sentido produzindo uma condensação semântico-formal". A segunda "tende a fazer essa união irromper em uma multiplicidade de relações sentido-forma, produzindo uma disjunção semântico-formal.”. (Endnotes) 


\section{Referências}

AMOSSY, R. Les idées reçues. Sémiologie du stéréotype. Paris: Nathan, 1991.

AMOSSY, R.; HERSCHBERG PIERROT, A. Stéréotypes et clichés: langue, discours, société. Paris: Nathan, 1997.

ARRIGUCCI JR., D. Coração partido. São Paulo: Cosac \& Naify, 2002.

MONDADA, L.; DUBOIS, D. Construção dos objetos de discurso e categorização: uma abordagem dos processos de referenciação. In: CAVALCANTE, M.; RODRIGUES, B.; CIULLA, A. Referenciação. São Paulo: Contexto, 2003. p. 17-52.

CHARAUDEAU, P.; MAINGUENEAU, Dominique. Dicionário de análise do discurso. São Paulo: Contexto, 2004.

CHARAUDEAU, P. Discurso político. Trad. Fabiana Komesu e Dílson Ferreira da Cruz. São Paulo: Contexto, 2006. . (1983, 1992). Linguagem e discurso. Trad. e org. Grupo NAD e CIAD-Rio. São Paulo: Contexto, 2008.

GRÉSILLON, A.; MAINGUENEAU, D. Polyphonie, proverbe et détournement ou un proverb peut en cacher unautre. Langages, v. 19, n.73, p.112-25, 1984.

KRIEG-PLANQUE, A. A noção de "fórmula" em análise do discurso: quadro teórico e metodológico. Trad. Salgado e Possenti. São Paulo: Parábola, 2010.

LEÃO, L.; SZÉLIGA, M. Julieta de bicicleta. São Paulo: Cortez, 2005.

MARCUSCHI, L. A. Da fala para a escrita: atividades de retextualização. São Paulo: Cortez, 2004.

MOTTA, R.M.; SALGADO, L. Fórmulas discursivas. São Paulo: Contexto, 2011.

ROCHA, R.; ZIGG, I. No caminho de alvinho tinha uma pedra... São Paulo: FTD, 1993.
SCHAPIRA, C. Les stéréotypes en français: proverbes et autres formules. Paris: Ophrys, 1999.

RIBEIRO, Patricia Ferreira Neves. Depois da bonança, mais quatro anos de castigo relações dialógicas em artigos de opinião. Linguagem em (Re)vista, Ano 07, n. 13/14. Niterói, 2012 - ISSN 1807-6378.

RIBEIRO, Patricia Ferreira Neves. Máxima, reenunciação e contemporaneidade. Revista Litteris, n. 9, março 2012 - ISSN 1983-7429.

RIBEIRO, Patricia Ferreira Neves. Estratégias de persuasão e de sedução na mídia impressa. In: PAULIUKONIS, Maria Aparecida Lino; GAVAZZI, Sigrid. (Org.). Texto e Discurso: mídia, literatura e ensino. Rio de Janeiro: Lucerna, 2003, p.120-131.

PAULIUKONIS, Maria Aparecida Lino; GOUVÊA, Lúcia Helena Martins; RIBEIRO, Patricia Ferreira Neves Ribeiro. Estratégias Argumentativas nos Discursos Sociais e suas Aplicações Didáticas. In: HENRIQUES, Claudio Cesar (Org.). Linguagem, conhecimento e aplicação: estudos de língua e linguística. Rio de Janeiro: Ed. Europa, 2003, p. 88-100. 